\title{
Research on Communication of Chinese Folk Dance Art in Mass Media Era
}

\author{
Jing Yang \\ Art Institute, Qiongzhou University, Sanya, 572000, China
}

Keywords: mass media; art communication; Chinese folk dance

\begin{abstract}
With continuous progress of science and technology, the information-based era has come; meanwhile, great changes have happen in communication of Chinese folk dance art. Except for changes in subjects and objects, there are also changes in the form and feature of content of folk dance. This paper will carry out analysis on features and content of Chinese folk dance art, and explain the changes of factors influencing communication under the background of mass media.
\end{abstract}

\section{Introduction}

In the past, the folk dance and art communication were two different disciplines, thus their research was independent. Combing folk dance art and communication together to research the communication of Chinese folk dance art is good for us to better know the changes of art communication. Chinese folk dance has more than 1,000-year history, with rich cultural deposits, and people at all social classes have demand for Chinese traditional dance art. In mass media era, Chinese folk dance art has been spread to all social classes to let all people enjoy artistic edification.

\section{Aesthetic characteristics and communication process of Chinese folk dance}

\section{Aesthetic characteristics of Chinese folk dance}

China is a country with a long history, and also a country with deep cultural deposits. Over thousands of years of development, the folk dance art has become an important part of Huaxia culture. Meanwhile, the folk dance also has certain characteristics. Firstly, Chinese folk dance has diversified characteristic. China is a multinational country with 56 nationalities; each nationality has different living habit and belief, as well as different dance style. For example, Mongolia dance is passionate and bold, showing Mongolia people's straightforwardness, open-mindedness, and manliness; as for peacock dance of Dai nationality, Dai people always love peacock, and the peacock dance also shows Dai people's longing for good life. Secondly, Chinese folk dance has open characteristic. Chinese nation is an open and confident nation; in the development process, each kind of Chinese folk dance will be influenced by dance art of other nationalities, absorb and borrow ideas from essence of other dance culture, and enrich its own content and artistic form. The mutual blending of 56 nationalities promotes mutual learning among dance arts, thus Chinese folk dance has open characteristic. Besides, Chinese folk dance art has popular characteristic. The folk dance originates from people; the common people create dance, thus the dance becomes popular and easy to be understood. The dance shows common people's spiritual pursuit and value idea. Therefore, the popularity of folk dance is its fundamental attribute.

\section{Communication process of Chinese folk dance}

If we want to analyze the communication process of Chinese folk dance, we must firstly know its artistic information. The object of folk dance art is its main artistic information; it not only can connect art communicator with receiver, but also can cause certain influence on communication effect of folk dance art. The effective communication is realized only after receiving the artistic information approved and accepted by the public; however, if the content of artistic information is broken away from the public at basic level, it will be similar to working behind closed doors. Therefore, in the communication process, the information of folk dance must accept the public's judgment and supervision so that the folk dance can be loved by people and it is good for communication of folk dance. The effective communication of artistic information can't be 
separated from communication media; when we use different communication media to communicate folk dance art, different features are shown. For example, although the live performance can cause cordial feeling and feeling of reality, the communication effect is limited, and the space of live performance is also limited, thus only limited audience can be influenced. With the development of science and technology, the new communication media such as newspaper, television, and network continuously emerge, and the scope and speed of communication of folk dance art are also improved, but it is difficult to obtain feedback information to art; therefore, we shall make comprehensive use of various kinds of communication media to improve communication effect.

\section{Characteristics of communication subject and object of Chinese folk dance art}

\section{Communication subject of Chinese folk dance art}

The folk dance communicators have diversified characteristic, and they include the creators and performers of folk dance art, as well as various kinds of communication media, etc. The communicators are initiators of communication activities of folk dance art; the quality of communication is not directly linked with quantity of communication, but the quality will determine each person's view of value. There is certain difference in communicators' personal quality, which will cause certain effect on art communication and even cause wrong communication of artistic information. In the past, in the communication of folk dance art, the performers spread art to the public through a way of artistic performance. However, in mass media era, the public can appreciate art through various kinds of media without directly facing performers. Therefore, in terms of certain layer, the communication media is not only the coomunication intermediary of art, but also the communicator.

\section{Communication object of Chinese folk dance art}

In terms of aesthetic view, the audiences of Chinese folk dance art have two features. Firstly, the audiences' perception is different. In order to be widely popular in the society, the artistic works must be accepted and appreciated by the audiences. However, the appreciation process of folk dance doesn't always exist; as for some works, there is slight repercussion while they are initially performed, but they are later widely spread; as for some works, they obtain roaring reputation at the beginning but can't stand time trial. There are great quantity of audiences, thus their perception is also different, which is also one of decisive factors of art communication effect. In addition, the audiences' perception also has the feature of identity, which is mainly reflected at the fact that the audiences in same period also show certain perception identity although individual has different aesthetic standard as for audiences under different era background; for instance, there is different popular art in different period.

\section{Economic and political demand of Chinese folk dance art}

The development of social economy is also influenced by folk dance art. Today, people's problem of food and clothing has been solved, and people start to seek for spiritual enjoyment and carry out active artistic activities; the folk dance meets people's artistic demand. The economic relation has certain effect on communication of folk dance art. As for drawing materials and information collection, the folk dance art needs to consume certain cost time; upon choreography, certain cost will be consumed; the performers' performance and propagandists' propaganda will also consume some costs; all those investments form the cost of dance art. In the art production, it is required to consider economic factor; if the final benefit is less than cost, the investors or initiators will run at a loss. If the artistic creation has a high cost and the public can't afford such cost, great limitations will be caused to art communication. Then, it is the influence of political demand on communication of folk dance. Generally speaking, as long as the folk dance conforms to governmental interests, its development will be supported, and the artistic works which will cause certain damage on country will be limited. 


\section{Analysis on factors influencing communication of Chinese folk dance art under background of mass media}

\section{Influence of communicators' artistic accomplishments}

The starting point of folk dance art communication activities is the communicator who is an important influence factor for artistic communication to realize its value. At present, China has many folk dance art communicators, but there is great difference in their respective artistic accomplishments; many art communicators even have wrong view of value, lack of basic moral cultivation, and have weak sense of responsibility for art communication; there is no doubt that those communicators will cause negative influence on art communication and damage the image of Chinese folk dance art. Therefore, in mass media era, the folk dance art communicators shall be strict with themselves, continuously improve their artistic accomplishments, reasonably get hold of value orientation of art, and contribute healthy and high-value art to people.

\section{Artistic content of folk dance}

As mentioned above, the artistic content of folk dance plays an important role in its communication. Only excellent artistic content and content close to people's life can be accepted by the public. Therefore, when the art creators create art, they shall select materials from people's life, and the content shall also show noble artistic pursuit, and conform to the public's value orientation. At present, the artistic information created by partial art creators is broken away from the public, and the value orientation also violates against social value orientation. This kind of artistic information must limit the communication of folk dance art. Therefore, upon creation, the folk dance art shall be closely linked with the public; the creators shall carefully listen to the public's suggestions and opinions, and the art created shall be inspiring and loved by the public.

\section{Communication media of folk dance art}

In order to realize true communication, the folk dance must depend on certain communication media, and the communication media plays an important role in the communication of folk dance art. Different communication media plays different role in art communication process. In traditional period, although the face-to-face from of artistic presentation is good for the audiences to perceive the art, this communication way can only realize partial communication effect. In new media era, various kinds of new communication media such as network and television expand communication scope, improves communication speed, and also enhance communication effect. however, each kind of communication media has its advantages and disadvantages. For example, although the television media can give live broadcasting of folk dance art, it is unable to effectively obtain the audiences' true feeling and evaluation on art; the network can make effective broadcasting of folk dance art and obtain feedback information, but there are still many people who can't contact the internet. Therefore, in order to effectively spread folk dance art, it is required to make full use of many kinds of media and exert advantages of each kind of media to form complementation.

\section{Audiences of folk dance art}

The art audiences are true audiences of folk dance art, and the communication value of folk dance can be truly reflected on audiences. However, the audiences' different age stages, different cultural levels, and different life experiences will cause difference in their feelings of content of folk dance art. In aesthetics of reception, the artistic research regards appreciators as one of research objects and pays great attention to audiences in communication activities. Two factors shall be considered when we analyze the communication of folk dance art from perspective of audiences. On one hand, the information of folk dance art shall conform to audiences' aesthetic characteristics. Different audiences have different artistic preference, thus the art communication content shall be targeted and the difference in preference can't be ignored. If we spread same content to all audiences, the audiences will be unable to understand artistic content, which further affects communication effect. On the other hand, the communication form of folk dance art shall conform to audiences' demand. In creation of folk dance art, the arrangement and performance of movements shall start from audiences' demand, and it is required to design suitable dance movements, section, and expression of feelings; meanwhile, the matching of performance lights, camera angle, editing, and selection of background music shall all take audiences' demand as basis. 


\section{Influence of social environment on communication}

The social environment mainly refers to social overall environment; it consists of corresponding economic base and superstructure, and it can be generally divided into view of value, moral standard, trend of times, political system, cultural background, and economic system, etc. The creators and audiences of Chinese folk dance art all live under Chinese political and economic environment; therefore, the current social background certainly has certain imitations on communication of folk dance art. The $20^{\text {th }}$ century has gone by; in the $21^{\text {st }}$ century, the knowledge-based economy is current topic of social economy, and new changes have happened in communication mode of folk dance art; many new communication subjects have emerged; furthermore, in current China, many folk dance art producers have appeared, and the folk dance art has formed industrial production. In mass media era, the distance between production and final consumption of folk dance information becomes shorter and shorter, and the changes also have happened in the communication carrier of folk dance art with a transition from paper carrier to electronic carrier, which greatly improves the communication effect of folk dance art.

\section{Communication effect of Chinese folk dance art in mass media era}

The continuous integration of art, science and technology, and economy results from the fact that the continuous enhancing of market economic competition gradually improves and enriches means and forms of communication of Chinese folk dance art, and greatly meets various consumption stratums' diversified demand for folk dance. With arrival of information era, great changes have happened in communication behaviors of folk dance art, new communication subjects greatly emerge, and the indirect communication way is gradually changed as direct communication way. The communication of folk dance art gradually steps into diversified era; the scope of communication becomes wider and wider and the speed of communication becomes quicker and quicker; people of different ages, different cultural levels, different territories, and different life experiences gradually join the audience group of folk dance art. Furthermore, the communication subjects of folk dance art also come from all parts of the country, and they select different communication media according to different social division of labor and different audience objects. Meanwhile, the function of communication media of folk dance art is increasingly enhanced with more and more diversified forms, which provides the public with diversified means to know folk dance and also guides the direction of communication of Chinese folk dance art.

\section{Conclusion}

In a word, in mass media era, the corresponding changes also have happened in the communication of folk dance art; meanwhile, there are certain requirements proposed to folk dance art. Only the art which is closely linked with the public and conforms to the public's aesthetic opinions can be better spread; meanwhile, in communication process, it is also required to make full use of various kinds of media and exert their respective advantages so as to jointly promote communication of Chinese national folk dance.

\section{References:}

[1] Li Xiang: Analysis and Comparison Research on Communication Ways of Dance [D], Yanbian University, 2011

[2] Cui Jinghan: Local Experience: Essence of Teaching of Chinese Folk dance [J], Art Education, 2010, (04).

[3] Yu Ping: Dance Culture and Aesthetics [M], China Renmin University Press, 2005

[4] Li Longsheng, Fei Lijun: Discussion on Characteristics and Boundary of Art Communication [J], Art \& Education, 2007, (06). 